\title{
MODELACIÓN HIDROLÓGICA DE LA CUENCA MAYLANCO UTILIZANDO HEC-HMS
}

\section{Mario A. Angulo y Oliver C. Saavedra}

\section{RESUMEN}

La modelación hidrológica de cuencas es una necesidad crucial en regiones con problemas de abastecimiento de agua y planificación de recursos hídricos como es el caso de la región metropolitana del departamento de Cochabamba. La cuenca Maylanco es una de las cuencas más importantes de la cuenca del río Rocha. En su territorio se encuentra el municipio de Sacaba, zona urbana de gran crecimiento. En este estudio se realizó la modelación de la cuenca Maylanco con el software HEC-HMS, el cual se utiliza para modelar tormentas de diseño, es decir, caudales máximos en un periodo específico de tiempo. Se realizó una recopilación de datos de la zona de estudio como la precipitaciones desde 1980 a 2016, mapas temáticos de la zona, ubicación de estaciones pluviométricas y modelos de elevación digital. Se analizaron y clasificaron estos datos para obtener información adicional necesaria para la modelación de la cuenca. Se establecieron periodos de retorno de 2, 25, 50, 75 y 100 años con los que se ejecutó el programa para obtener caudales máximos. Se realizaron campañas de medición de caudales en puntos específicos para comparar los caudales observados con los obtenidos mediante la modelación. Se tomaron estaciones con registros de precipitaciones recientes y se analizaron las precipitaciones del primer trimestre de 2018 para identificar eventos para calibrar el modelo. Se seleccionó como punto de calibración la estación hidrométrica "El Abra" que registra el nivel del agua en ese punto cada 15 minutos. Se comparó el volumen en metros cúbicos generado por la simulación del evento con el volumen estimado por los registros de nivel y medición de caudal obteniendo una diferencia del $9 \%$ respecto al caudal estimado, lo cual es aceptable. Actualmente el modelo calibrado puede simular los hidrogramas de las sub-cuencas para determinar la variabilidad de las respuestas hidrológicas en la cuenca Maylanco. Este modelo puede ser utilizado para realizar pronósticos de tormentas futuras y determinar franjas de seguridad para ser considerados con los planes de uso de suelo en la zona.

Palabras Clave: Cuenca Maylanco, Sacaba, Río Rocha, HEC-HMS, Modelo Hidrológico.

DOI: $10.23881 /$ idupbo.018.1-4i 